\title{
The effects of the bacterial interaction with visible-light responsive titania photocatalyst on the bactericidal performance Chia-Liang Cheng1,2, Der-Shan Sun ${ }^{3,4}$, Wen-Chen Chu ${ }^{5}$, Yao-Hsuan Tseng, Han-Chen $\mathrm{Ho}^{7}$, Jia-Bin Wang1, Pei-Hua Chung ${ }^{1}$, Jiann-Hwa Chen ${ }^{8}$, Pei- Jane Tsai ${ }^{9}$, Nien-Tsung Lin ${ }^{10}$, Mei-Shiuan $\mathrm{Yu}^{10}$ and Hsin-Hou Chang ${ }^{* 2,3,4}$
}

Address: ${ }^{1}$ Department of Physics, National Dong-Hwa University, Hualien, Taiwan, ${ }^{2}$ Nanotechnology Research Center, National Dong-Hwa University, Hualien, Taiwan, ${ }^{3}$ Institute of Molecular Biology and Human Genetics, Tzu-Chi University, Hualien, Taiwan, ${ }^{4}$ Institute of Medical Science, Tzu-Chi University, Hualien, Taiwan, ${ }^{5}$ Department of Life Science, Tzu-Chi University, Hualien, Taiwan, ${ }^{6}$ Department of Chemical Engineering, National Taiwan University of Science and Technology, Taipei, Taiwan, ${ }^{7}$ Department of Anatomy, Tzu-Chi University, Hualien, Taiwan, ${ }^{8}$ Institute of Molecular Biology, National Chung Hsing University, Taichung, Taiwan, ' Institute of Medical Biotechnology, Tzu-Chi University, Hualien, Taiwan and ${ }^{10}$ Institute of Microbiology, Immunology and Molecular Medicine, Tzu-Chi University, Hualien, Taiwan

Email: Chia-Liang Cheng - clcheng@mail.ndhu.edu.tw; Der-Shan Sun - dssun@mail.tcu.edu.tw; WenChen Chu - sheila731110@yahoo.com.tw; Yao-Hsuan Tseng - tyh@ mail.ntust.edu.tw; Han-Chen Ho - hcho@mail.tcu.edu.tw; JiaBin Wang - ben1223w@yahoo.com.tw; Pei-Hua Chung - m9314001@gmail.com; Jiann-Hwa Chen - jhchen@dragon.nchu.edu.tw; PeiJane Tsai - pjtsai@mail.tcu.edu.tw; Nien-Tsung Lin - ntlin@mail.tcu.edu.tw; Mei-Shiuan Yu - meishiuan@mail.tcu.edu.tw; HsinHou Chang* - hhchang@mail.tcu.edu.tw

* Corresponding author

Published: 15 January 2009

Journal of Biomedical Science 2009, 16:7 doi:10.1186/1423-0127-16-7

This article is available from: http://www.jbiomedsci.com/content/l6/l/7

(C) 2009 Cheng et al; licensee BioMed Central Ltd.

This is an Open Access article distributed under the terms of the Creative Commons Attribution License (http://creativecommons.org/licenses/by/2.0), which permits unrestricted use, distribution, and reproduction in any medium, provided the original work is properly cited.
Received: 24 October 2008

Accepted: 15 January 2009

\begin{abstract}
Bactericidal activity of traditional titanium dioxide $\left(\mathrm{TiO}_{2}\right)$ photocatalyst is effective only upon irradiation by ultraviolet light, which restricts the potential applications of $\mathrm{TiO}_{2}$ for use in our living environments. Recently carbon-containing $\mathrm{TiO}_{2}$ was found to be photoactive at visible-light illumination that affords the potential to overcome this problem; although, the bactericidal activity of these photocatalysts is relatively lower than conventional disinfectants. Evidenced from scanning electron microscopy and confocal Raman spectral mapping analysis, we found the interaction with bacteria was significantly enhanced in these anatase/rutile mixed-phase carbon-containing $\mathrm{TiO}_{2}$. Bacteria-killing experiments indicate that a significantly higher proportion of all tested pathogens including Staphylococcus aureus, Shigella flexneri and Acinetobacter baumannii, were eliminated by the new nanoparticle with higher bacterial interaction property. These findings suggest the created materials with high bacterial interaction ability might be a useful strategy to improve the antimicrobial activity of visible-light-activated $\mathrm{TiO}_{2}$.
\end{abstract}

\section{Background}

The widespread use of antibiotics and the emergence of more resistant and virulent strains of microorganisms [13] have caused an urgent need to develop alternative sterilization technologies. Using the superb photocatalytic effect of titanium dioxide $\left(\mathrm{TiO}_{2}\right)$ is a conceptually feasible technology for this material is easy and inexpensive to produce in industrial scale. Photocatalytic $\mathrm{TiO}_{2}$ substrates have been shown to eliminate organic compounds and to function as disinfectants [4]. Upon ultraviolet (UV) light excitation, the photon energy excites valence band electron and generates pairs of electrons and holes (electron- 
vacancy in valence band) that diffuse and are trapped on or near the $\mathrm{TiO}_{2}$ surface. These excited electrons and holes have strong reducing and oxidizing activity and react with atmospheric water and oxygen to yield reactive species such as hydroxyl radicals $(\cdot \mathrm{OH})$ and superoxide anions $\left(\mathrm{O}_{2}^{-}\right)$[5]. These radicals, $\mathrm{OH}$ and $\mathrm{O}_{2}{ }^{-}$are extremely reactive upon contact with organic compounds. Complete oxidation of organic compounds and bacterial cells to carbon dioxide could be achieved [6,7]. Reactive oxygen species (ROS), such as $\mathrm{OH}, \mathrm{O}_{2}{ }^{-}$, and hydrogen peroxide $\left(\mathrm{H}_{2} \mathrm{O}_{2}\right)$ generated on the light irradiated $\mathrm{TiO}_{2}$ surfaces, were shown to operate in concert to attack polyunsaturated phospholipids in bacteria [4]. Traditional $\mathrm{TiO}_{2}$ photocatalyst, however, is effective only upon irradiation of UV-light at levels that would also induce serious damage to human cells. This greatly restricts the potential applications of $\mathrm{TiO}_{2}$ substrates for use in our living environments. Recently, nitrogen or metal ion-doped anatase based $\mathrm{TiO}_{2}$ photocatalysts have been identified to be active upon visible-light illumination $[8,9]$, offering the possibility to overcome this problem.

It is believed that nanometer-sized anatase phase particles have large surface area are efficient for the decomposition of pollutants in air and in water [10]. Furthermore, it is also found that the presence of anatase and rutile phases is important in some of the photocatalytic reactions where oxygen is used as electron acceptor [10]. Transmission electron microscopy studies also revealed that commercial $\mathrm{TiO} 2$ powder Degussa (P-25) consisting both anatase and rutile phases [11]. However, in these studies, the photocatalytic activities were induced under UV irradiation (wavelength $<380 \mathrm{~nm}$ ). Previously, we have produced carbon-containing $\mathrm{TiO}_{2}$ in two different calcination temperatures $\left(150^{\circ} \mathrm{C}\right.$ and $\left.200^{\circ} \mathrm{C}\right)$ resulted in two different nano-crystals (labeled as C150 and C200, respectively) with photocatalytic activity in the visible-light range [12]. These materials seem to be more convenient to apply in our living environment than the commercial UV responsive photocatalysts. The antibacterial activity of visiblelight responsive photocatalysts has been reported by several groups [13-15]. Since photocatalyst-based anti-microbial technologies are still under development, the antibacterial activity of these materials does not match to that of conventional chemical disinfectants $[13,16]$. To improve the antibacterial activity, previous studies were mainly focused on the photocatalysis properties $[17,18]$, while the photocatalyst-bacterial interactions were rarely discussed.

In this present study, scaning electron microscopy and confocal Raman spectrscopy were used to study different photocatalysts interact with pathogens. The photocatalyst-bacterial interaction properties were then compared to the bactericidal activity of respective photocatalysts. To further investigate whether the antibacterial effect can be generally applied to human pathogens, we tested several human pathogens including Staphylococcus aureus, Shigella flexneri and Acinetobacter baumannii. Among these bacteria, $S$. flexneri is a food-borne pathogen, which is usually found in contaminated water, plants, and sewage [19-22], and frequently leads to outbreaks in regions with poor sanitary conditions $[21,23]$. S. aureus is a exotoxin producing pathogen which can cause diseases such as food-borne diseases, soft tissue infections, and toxic shock syndrome in humans[19]. The emergence and rapid spread of multidrug-resistant $A$. baumannii isolates causing nosocomial infections are of great concern worldwide [24]. The antimicrobial performance of the visible-light responsive titania catalysts against these bacteria will be compared.

\section{Materials and methods \\ Preparation of $\mathrm{TiO}_{2}, \mathrm{Cl} 50$ and $\mathrm{C2} 20$ nanoparticles}

Carbon-containing mixed phase nano-structured $\mathrm{TiO}_{2}$ powders were prepared using a modified sol-gel method. The produced powders were subjected to calcination at $150^{\circ} \mathrm{C}$ and $200^{\circ} \mathrm{C}$, and named as $\mathrm{C} 150$ and C200, respectively. Details in preparation of C150 and C200, structural properties, the sizes of primary particles, light absorption, etc. have been reported elsewhere [12]. In our previous study [12], we found the $\mathrm{C} 200$ has a unique anatase/rutile mixed crystalline phases that exhibits strong visible-light absorption and photocatalytic effects. The photocatalytic studies have been reported previously $[12,25,26]$. In these $\mathrm{TiO}_{2}$, carbons exist in an amorphous form as seen in the Raman spectra, and the carbon contents were estimated using $\mathrm{x}$-ray photoelectron spectroscopy to be approximately 30 atomic \% on the surface (data not shown). One commercially available $\mathrm{TiO}_{2}$ nanopowder (UV100, Sachtleben, Germany), that can exert the photocatalytic property only when illuminated by UV light, was used for comparison. Since C150 and C200 samples often aggregate into larger cluster due to surface charges, Van der Waals interactions, we dispersed the aggregates using sonication (Transsonic digital TP680DH, Ultrasonic cleaning Co. Singapore, Singapore) before the bacteria-killing or bacteria-photocatalyst interaction experiments.

\section{Confocal Raman spectral mapping}

Confocal Raman mapping was carried out with a confocal Raman spectrometer using $488 \mathrm{~nm}$ excitation wavelength ( $\alpha$-SNOM, Witec, Germany). The confocal Raman mapping has a spatial resolution of $\sim 250 \mathrm{~nm}$; typical scan were performed in an area of $10 \times 10 \mu \mathrm{m}^{2}$ area and in air. The mapping consisted of $0.2 \mu \mathrm{m}$ in each step in both the $\mathrm{x}$ and y directions, with specific Raman signals of the interested sample components are plotted to form a 2-D map to reveal the structural distribution of the interested structures. The bacteria-nanoparticle images were taken after $20 \mu \mathrm{l}$ of nanoparticles $(10 \mathrm{mg} / \mathrm{ml})$ and bacteria $\left(1 \times 10^{6}\right.$ 
$\mathrm{CFU} / \mathrm{ml}$ ) suspensions in $\mathrm{H}_{2} \mathrm{O}$ were spread on cover glasses and dry. Laser power were kept low (less than 1 $\mathrm{mW}$ ) to avoid damaging the test samples, both the $\mathrm{TiO}_{2}$ and the bacteria.

\section{Scanning electron microscopic imaging}

Scanning electron microscopic (SEM) analysis was performed as previously described [27-30]. The images were obtained using a JEM-3010 scanning electron microscope (JEOL, Japan) equipped with energy dispersive x-ray spectrometer (EDS) for the chemical elemental analysis to observe the surface morphology of the tested $\mathrm{TiO}_{2}$ nanoparticles. To observe the interaction of microbes and $\mathrm{TiO}_{2}$ samples, bacteria and $\mathrm{TiO}_{2}$ powders were mixed and subjected to photocatalytic reaction as described in next sections. After the reaction, the samples were transferred to cover-glasses and fixed by $2.5 \%$ glutaraldehyde in $0.1 \mathrm{M}$ phosphate buffer, then $1 \%$ osmium tetroxide in $0.1 \mathrm{M}$ phosphate buffer, $\mathrm{pH} 7.3$, and then subjected to a series of alcohol dehydration, critical point drying procedures, and gold coating [27] and observed under a scanning electron microscope at $15 \mathrm{kV}$ (Hitachi S-4700, Hitachi, Japan). At least three different areas were randomly selected for photography at each magnification; representative data are shown.

\section{Bacterial strains and culture}

Basic bacterial cultural methods were performed as previously described [13,31]. Clinical isolated S. flexneri was collected from a shigellosis outbreak in central Taiwan in 1996 [23]. A. baumannii, pan-drug resistant A. baumannii and $S$. aureus were clinical isolates from Buddhist Tzu-Chi General Hospital in Hualien, Taiwan. All isolates were initially differentiated into Gram positive and Gram-negative strains by a standard staining procedure. The bacteria were cultured in tryptic soy broth supplemented with $0.5 \%$ yeast extract (TSBY) and $\mathrm{LB}$ at $37^{\circ} \mathrm{C}$ for $16 \mathrm{hr}$, and then identified by biochemical methods according to routine clinical laboratory procedures [32]. S. flexneri, A. baumannii and pan-drug resistant $A$. baumannii were maintained and grown in LB medium or LB agar at $37^{\circ} \mathrm{C}$. Bacterium S. aureus was grown in TSBY broth or TSBY broth agar (MDBio, Inc. Taipei, Taiwan) at $37^{\circ} \mathrm{C}$. All bacteria isolates were stored in $50 \%$ glycerol $(\mathrm{V} / \mathrm{V})$ in culture medium at $-80^{\circ} \mathrm{C}$ before use. To reactivate bacteria from frozen stocks, $25 \mu$ l bacterial stock solution was transferred to a test tube containing $5 \mathrm{ml}$ of freshly prepared culture medium and then incubated at $37^{\circ} \mathrm{C}$ under agitation overnight (16-18 hr).

\section{Bactericidal effects of the $\mathrm{TiO}_{2}$ nanoparticles}

In this study, bacterial concentrations were either determined by the standard plating method or inferred from optical density readings at $600 \mathrm{~nm}\left(\mathrm{OD}_{600}\right)$. For each bacterium, a factor for converting the $\mathrm{OD}_{600}$ values of the bac- terial culture to concentration $(\mathrm{CFU} / \mathrm{ml})$ was calculated as the followings. A fresh bacterial culture was diluted by factors of $10^{-1}$ to $10^{-7}$, and $\mathrm{OD}_{600}$ of these dilutions was measured. Bacterial concentrations of these dilutions were determined using standard plating method. The $\mathrm{OD}_{600}$ values were plotted against the bacterial concentrations' log values, and the conversion factors for particular bacteria were calculated. The conversion factor for $S$. aureus, for example, was calculated to be $1 \times 10^{8} \mathrm{CFU} / \mathrm{ml}$ per $\mathrm{OD}_{600}$ by this method.

In order to determine the bactericidal effects of the $\mathrm{TiO}_{2}$ nanoparticles, $200 \mu \mathrm{l}$ of bacterial overnight culture was transferred into $5 \mathrm{ml}$ of culture medium and incubated at $37^{\circ} \mathrm{C}$ until an $\mathrm{OD}_{600}$ of 0.3 to 0.6 (log phase) was reached. The bacterial concentrations were calculated using the conversion factor for the bacteria, and the cultures were diluted to $5 \times 10^{5} \mathrm{CFU} / \mathrm{ml}$ with culture medium. Fifty micro liters of the bacterial culture $\left(2.5 \times 10^{4} \mathrm{CFU}\right)$ were mixed with the $\mathrm{TiO}_{2}$ nanoparticles $(200 \mu \mathrm{g} / \mathrm{ml}$ in $150 \mu \mathrm{l}$ normal saline) using a plastic yellow tip and placed onto a 24-well cell culture dish. The cell culture dish was then placed under an incandescent lamp (Classictone incandescent lamp, 60W, Philips, Taiwan) for photocatalytic reaction, and a light meter (model LX-102, Lutron Electronic Enterprises, Taiwan) was used to record the illumination density. In the dose-dependence experiments, illuminations were carried out for $5 \mathrm{~min}$ at a distance of 5 and $15 \mathrm{~cm}$ from the lamp, corresponding to the illumination density of $3 \times 10^{4}$, and $5 \times 10^{2}$ lux (lumen/m²) $(90$ and $10 \mathrm{~mW} / \mathrm{cm}^{2}$ ), respectively. In the kinetic analysis experiments, illuminations were carried out for 1, 5, 10, 20 , and $40 \mathrm{~min}$ at a distance of $5 \mathrm{~cm}$, corresponding to an illumination density of $3 \times 10^{4}$ lux $\left(90 \mathrm{~mW} / \mathrm{cm}^{2}\right)$. After illumination, the bacterial solutions were recovered from the 24-well cell culture dishes, and an aliquot of fresh culture medium $(250 \mu \mathrm{l})$ was used to flush the wells through repeatedly pipetting to further collect the residual bacteria on the wells of the culture dish. The two bacterial solutions were pooled to make a total of $350 \mu$ l. The bacterial concentration was determined by the standard plating method immediately after the bacterial collection, and percentage of surviving bacteria was calculated. Polystyrene latex beads were purchased from Sigma-Aldrich (Saint Louis, Mo, USA) and used as negative controls.

\section{Statistical analysis}

All results were calculated from data of three independent experiments. T-test was used to assess statistical significance of differences in results of the antimicrobial effects. A $P$ value of less than $0.05(P<0.05)$ was considered significant. The statistical tests were carried out and output to graphs using the Microsoft Excel (Microsoft Taiwan, Taipei, Taiwan) and SigmaPlot (Systat Software, Point Richmond, CA, USA) software. 


\section{Results}

\section{Electron microscopic and Raman spectroscopic analysis}

The interaction of the bacteria and $\mathrm{TiO}_{2}$ nanoparticles was observed using scanning electron microscope (Fig. 1). Fig. 1A, B depicts the SEM images of the aggregated C150 and $\mathrm{C} 200 \mathrm{TiO}_{2}$ nanoparticles. The sizes appear larger that the dispersed primary particles due to particle aggregations. Fig. $1 \mathrm{C}$ is the Energy dispersive $\mathrm{x}$-ray spectroscopy (EDS) that indicates the elemental analysis of the investigated nanoparticles. As shown in the EDS spectrum, the investigated $\mathrm{TiO}_{2}$ nanoparticles contain carbons in addition to $\mathrm{Ti}$ and oxygen. The carbon contents was estimated to be 1 weight \% or 10 atomic \% from the EDS spectrum. In Fig. $1 \mathrm{D}-\mathrm{F}$, the SEM images revealed the interaction between the tested $\mathrm{TiO}_{2}$ samples and the $S$. aureus. As seen in these images, the nanometer-sized $\mathrm{TiO}_{2}$ can effectively interact with the bacteria $S$. aureus. However, commercial UV100 $\mathrm{TiO}_{2}$ that works as photosensitizer only in the UV range of the light spectrum, the morphology of the bacteria was not affected when interacted with the $\mathrm{TiO}_{2}$ upon visiblelight illumination (Fig. 1D). For the C150 sample, already some effect was seen on bacterial morphology (Fig. 1E). As to the C200 sample, the morphology of the bacteria was strongly altered due to the interaction with the $\mathrm{TiO}_{2}$ under visible-light illumination (Fig. 1F). The SEM investigation showed that C200 sample upon visible-light illumination would spread over the bacterial surface, although bare C200 sample showed aggregation due to their nanometer sizes and strong van der Waals force interaction. This observation is consistent with our bacterial killing test for different strains of bacteria used, and the results will be shown in the following sections.
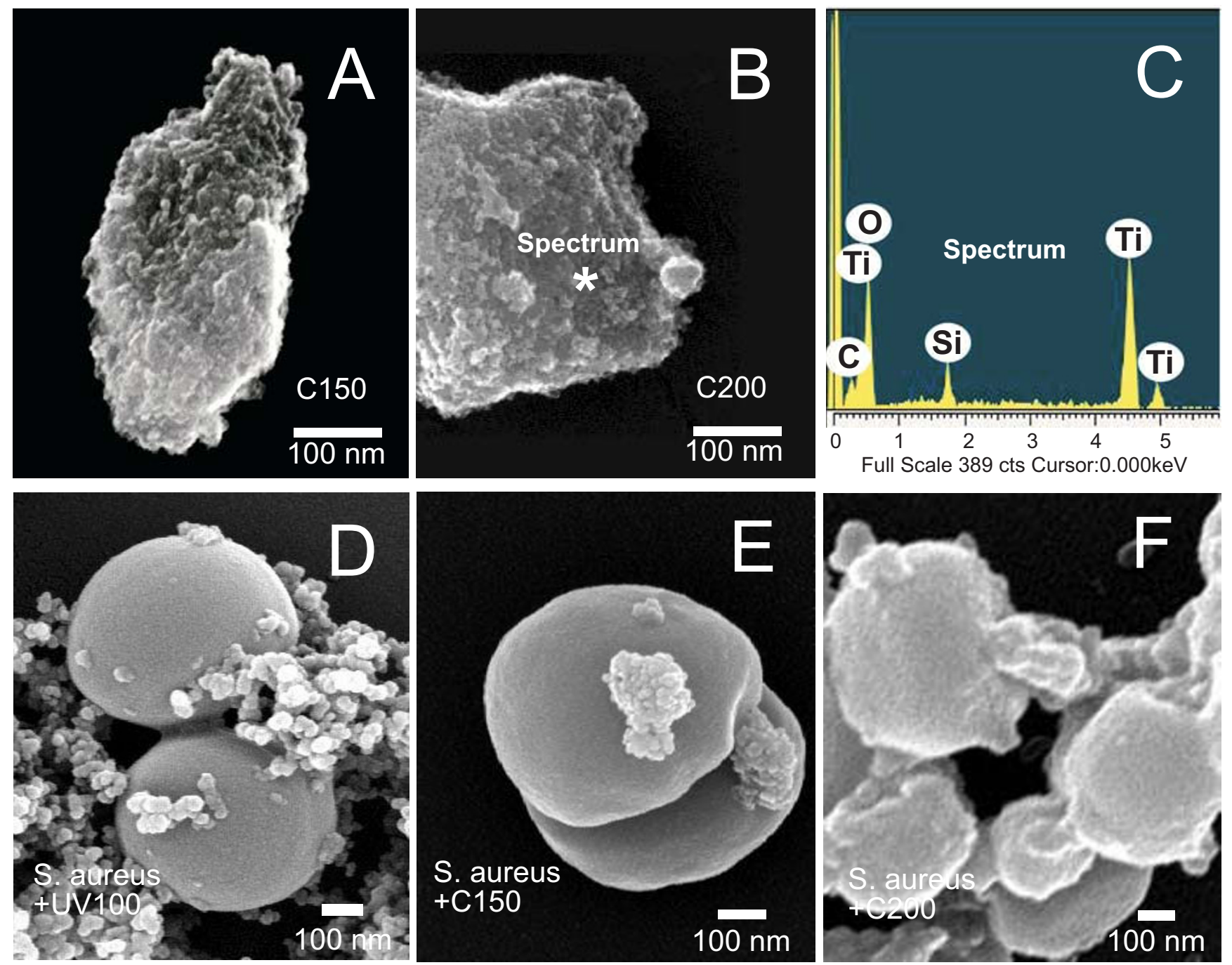

Figure I

Scanning electron microscope images of the $\mathrm{TiO}_{2}$ nanoparticles. (A) CI50, (B) C200, (C) EDS elemental spectrum of C200, (D) S. aureus and UVI00, (E) S. aureus and CI50, and (F) S. aureus and C200. Scale bars: $100 \mathrm{~nm}$. 
However, the observation using the scanning electron microscope can only be achieved in high vacuum environment; and the samples required gold coating for imaging. This may cause the complication on the test bacterial sam- ples. To analyze the bacterial samples in a relatively noninvasive way, the bacterial interaction with $\mathrm{TiO}_{2}$ was further observed with confocal Raman spectroscopic mapping in ambient. In Fig. 2, the Raman spectra of C150,
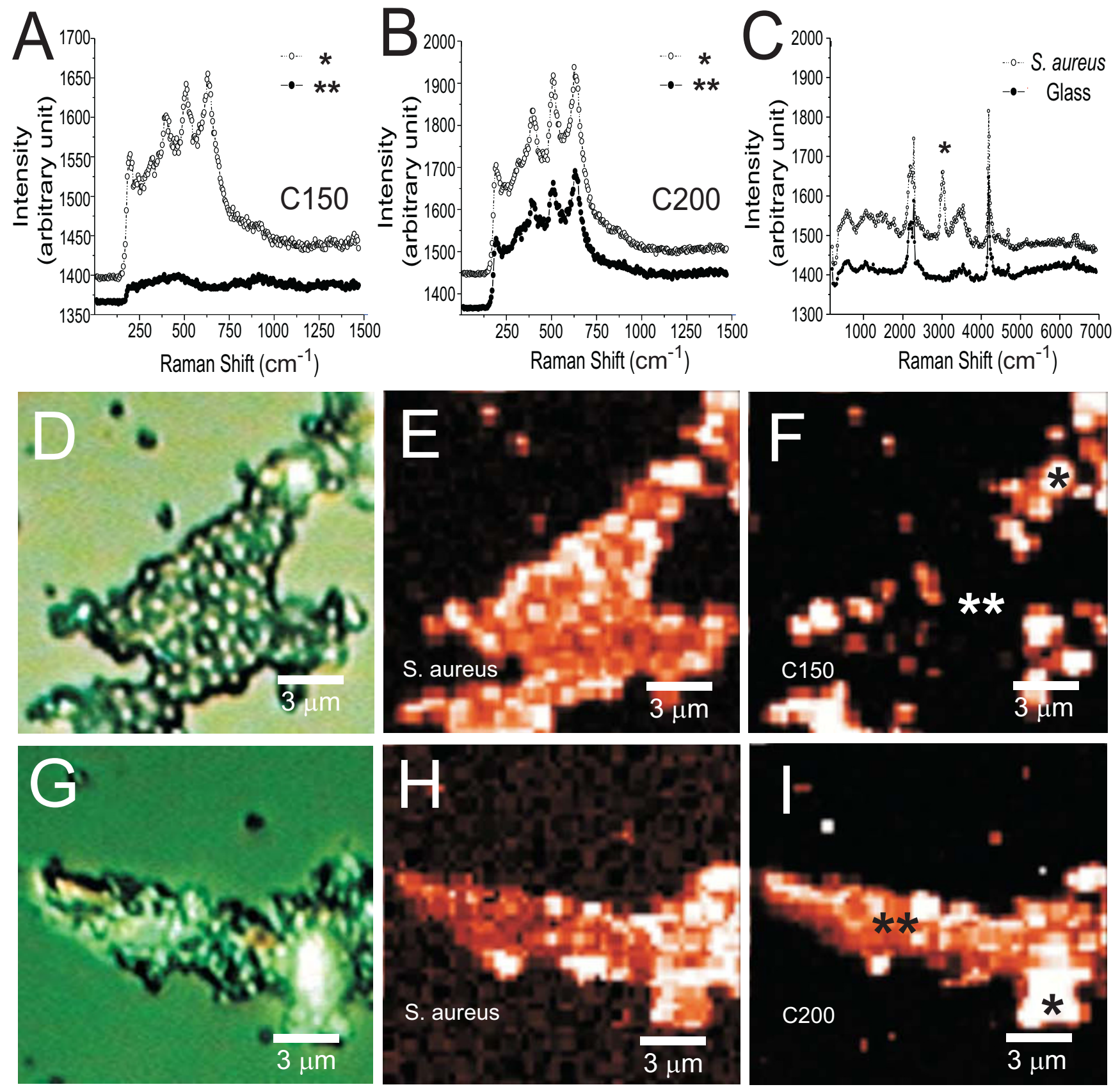

Figure 2

Raman spectra and confocal Raman mapping of the interaction of $S$. aureus with $\mathrm{TiO}_{2}$ nanoparticles. The Raman spectra of (A) CI50, (B) C200 and (C) S. aureus. Optical image of the aggregated bacteria S. aureus interacting with CI50 (D), confocal Raman mapping of the $S$. aureus Raman signals (E) and confocal Raman mapping of CI50 (F), optical image of the aggregated bacteria $S$. aureus interacting with $C 200(\mathrm{G})$, confocal Raman mapping of the S. aureus signals $(\mathrm{H})$ and confocal Raman mapping of C200 (I). 
C200, and the S. aureus (Fig. 2A-C) and the spectra of the corresponding positions indicated in the confocal Raman mapping images (Fig. 2E, F and Fig. 2H, I) are shown, respectively. In the Raman spectra, the spectral assignments are; 586, $682 \mathrm{~cm}^{-1}$ for anatase phase; $421,461 \mathrm{~cm}$ ${ }^{1}$ for rutile phase of the $\mathrm{TiO}_{2}$ crystal structures. The unique Raman peak at $3000 \mathrm{~cm}^{-1}$ was used as a marker for imaging the position of bacteria S. aureus (Fig. 2C). Optical microscopy images show the typical examples of mixed aggregates of C150 and C200 with the S. aureus (Fig. 2D, $\mathrm{G})$; and the signal of Raman mapping further reveals the distribution and the position of bacteria or $\mathrm{TiO}_{2}$ (Fig. 2E, F and Fig. 2H, I). For the C150 (Fig. 2F), the bright spots indicated the locked C150 Raman signals. It appears randomly across the bacteria $S$. aureus (the bright images in Fig. 2E). For the sample C200, the Raman mapping for both the $S$. aureus and the C200 completely overlapped, suggesting a uniform coverage of the $\mathrm{TiO}_{2}$ on the bacteria $S$. aureus. This observation is completely in agreement with the SEM observation (Fig. 1E, 1F). The result indicates C200 sample has better interaction with the observed bacteria $S$. aureus.

\section{Killing of S. aureus by $\mathrm{Cl} 50$ and $\mathrm{C200}$}

To compare the bactericidal activities of the $\mathrm{TiO}_{2}$ nanoparticles, we mixed $2.5 \times 10^{4} \mathrm{CFU} \mathrm{S}$. aureus with $30 \mu \mathrm{g}$ of UV100, C150, or C200 in $200 \mu \mathrm{l}$ solutions and irradiated the solutions with $3 \times 10^{4}$ lux visible-light for $5 \mathrm{~min}$. After irradiation, bacteria solutions were recovered and the number of surviving bacteria was determined by standard plating-out method. Latex beads were used as a negative control. As shown in Fig. 3, C200 exhibited a significantly greater ability to reduce $S$. aureus number compared to latex beads and UV100 (Fig. $3,{ }^{*} P<0.05,{ }^{* *} P<0.01$ ).

To obtain dose dependent and kinetic data for $S$. aureus with C200 substrates, we further analyzed the effects of illumination by visible-light at various time points or at

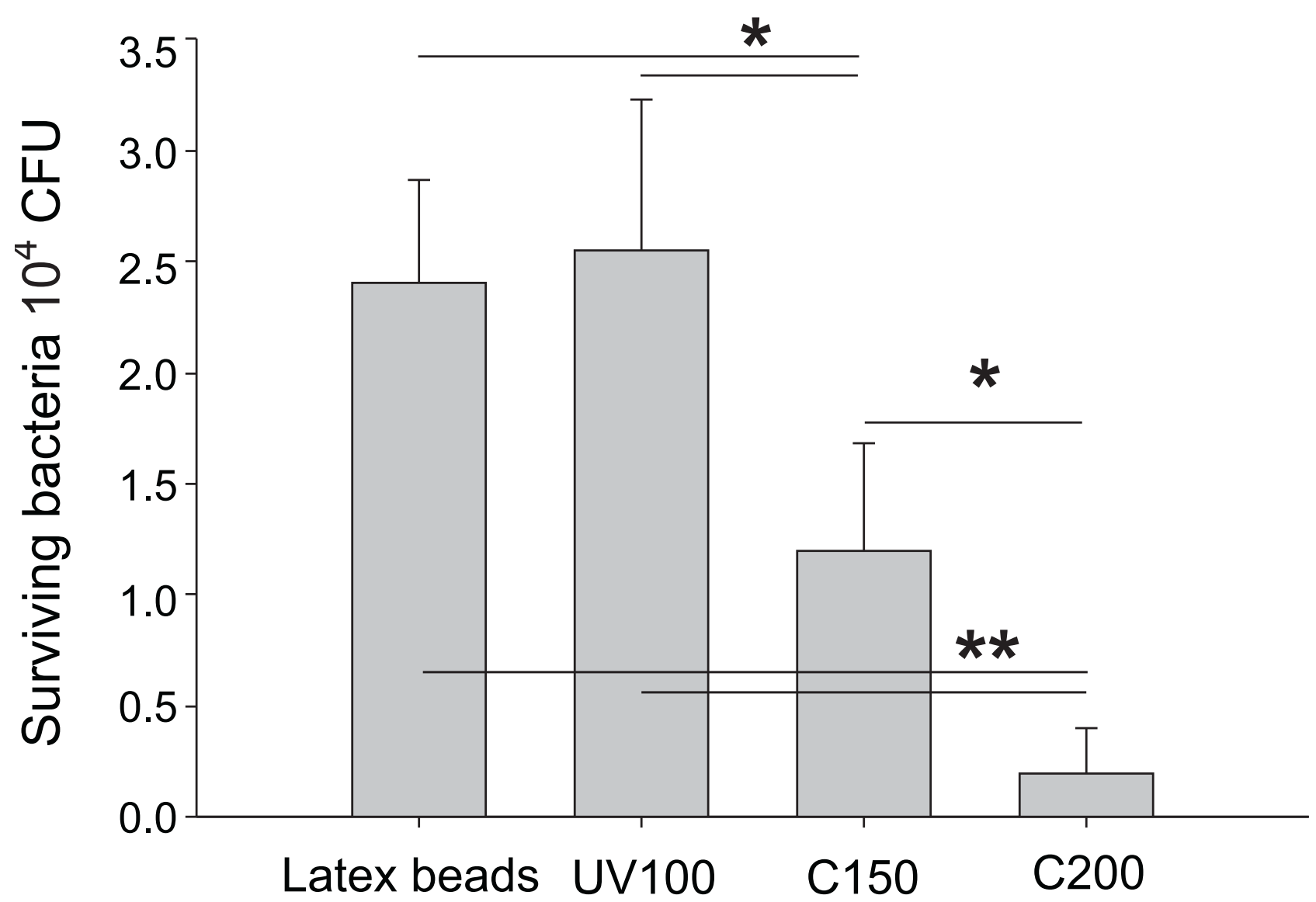

Figure 3

Bactericidal activity of UVI00, CI50 and C200 against S. aureus. Illumination was carried out at a light density of $3 \times$ $10^{4}$ lux for 5 min. $* P<0.05$, $* * P<0.01$. Latex beads were used as negative controls. 
various distances $(5 \mathrm{~cm}, 15 \mathrm{~cm}$, and with different illumination intensities of $3 \times 10^{4}$ and $5 \times 10^{2} \mathrm{lux}$ ) (Fig. 4). The results show that $\mathrm{C} 200$ substrates could kill $S$. aureus in minutes when exposed to various degrees of illumination by visible-light (Fig. 4A, B). Even though the bacteria killing efficiency in both C150 and C200 groups were significantly greater than the comparing UV100 groups (Fig. 4A, $\left.4 \mathrm{~B},{ }^{* *} P<0.01 ;{ }^{*} P<0.05\right)$, C200 still has superior performance when compared to C150 groups (Fig. 4A, $3 \times$ $10^{4}$ lux groups; $4 \mathrm{~B}, 5 \mathrm{~min}$ to 40 min groups, $+P<0.05$ ). The observation is in agreement with both the SEM and Raman observations that C200 sample exhibited distinct performance when interacting with the tested bacteria.

\section{Bacteria-killing experiment for other pathogens}

Bactericidal activities of C150 and C200 on other human pathogens including $A$. baumannii, pan-drug resistant $A$. baumannii and S. flexneri were also examined. C200 demonstrated significantly higher effectiveness in killing of all tested bacteria, as compared to C150 and UV100 (Fig. 5).

\section{Discussion}

Urbanization, population growth and heavy traveling enable infectious diseases to quickly spread worldwide from one local area. Photocatalyst has the potential for use in a variety of settings to reduce the transmission of pathogens in public environments. The emergence of increasingly virulent and antibiotic resistant pathogens in hospital settings $[1,3]$ provides another motivation for the development of alternative disinfection approaches using photocatalyst. There are several advantages to use the visible-light responsive photocatalyst such as titania. First, for safety consideration, visible light is a relatively safer light source as compared to UV irradiation [33]. Exposure to UV light at the necessary levels, would cause great damage of skin and eye tissues for humans [33-35]; thus limiting the use of conventional UV activated $\mathrm{TiO}_{2}$ substrates in environments where humans would be exposed. The visible-light activated photocatalyst offers a perfect alternative for use as a disinfectant in public areas. Second, because $\mathrm{TiO}_{2}$ is a chemically stable and inert material, it could continuously exert antimicrobial action when illuminated by light. Third, the bactericidal activity can be switched on and off or modulated by controlling the light intensity. In addition, from efficiency point of view, commercial titania absorbs only the UV range estimated 2-3\% of solar light impinging on the Earth's surface [36] when used for an outdoor setting. The advantages of the visiblelight responsive photocatalyst might be complementary to existing disinfectants and provide the potential for developing a variety of alternative antimicrobial applications. To extend the light-absorption into visible-light range, doping with transition ions and/or anions (negative ions) is a commonly used method. By which it creates intra-band gap states close to the conduction or valence band edges that induces visible-light absorption at the sub-band gap energies $[9,36]$. In some cases, the doped materials also are able to inhibit the charge recombination, thereby increase the photocatalytic activity [36-39]. Using such approach, many studies have shown to develop titania photocatalyst with antimicrobial activity in the visible-light range [13-15,38-46]. In these studies, anions such as sulfur, nitrogen and carbon, and metal ions such as neodymium, tungsten, and platinum were used for doping titania. The photocatalytic- and antimicrobial-performance of these dopants are different because the various roles of the doped materials in trapping electrons and/or holes on the surface.

Besides photocatalytic activity, there are still other unidentified factors affect the antimicrobial activity. For example, catalysts may have similar photocatalytic activity but with different bactericidal performance as observed in the study using titania-coated nickel ferrite [40]. Anatasetitania-coated nickel ferrite and brookite-titania-coated nickel ferrite have a similar photocatalytic reaction rate, while the former one has a superior bacterial-inactivation response [40]. This indicates the physical properties such as bacterium-catalyst interactions might influence the antimicrobial outcome.

To analyze the influence of bacterium-catalyst interactions on the antimicrobial performance, we used C150 and C200 titania catalysts. Previously we found that both C150 and C200 samples have a similar visible light absorption pattern [12]. C200 nanocrystals, however, contain mixed anatase and rutile phases that resulted in interface states in the mixed surface energy structures, as compared with uniform anatase phase structure of C150 nanocrystals [12]. The distinct bacterial interaction behaviors of the C150 and C200, as observed in the SEM and Raman mapping in this study, presumably are attributed to the existence of different structural complexity. The interactions between $\mathrm{TiO}_{2}$ with biomolecules were rarely discussed. It was shown that various sol-gel treatments can change the property of $\mathrm{TiO}_{2}$ surfaces $[47,48]$. It was also shown that different $\mathrm{TiO}_{2}$ crystal surfaces indeed have different affinities toward cellular protein fibronectin [49]. In addition, carbon-coated $\mathrm{TiO}_{2}$ samples showed high affinity and high photoactivity towards organic compound methylene blue $[48,50]$. Since bacterial surfaces express various organic components and proteins, it is not surprising that the bacteria would have a preferential interaction with specific catalyst. Using scanning electron microscopy and confocal Raman mapping techniques, here we successfully demonstrated that better bacterialinteraction is associated with better pathogen-killing performance when C200 samples were tested in bactericidal experiments. 

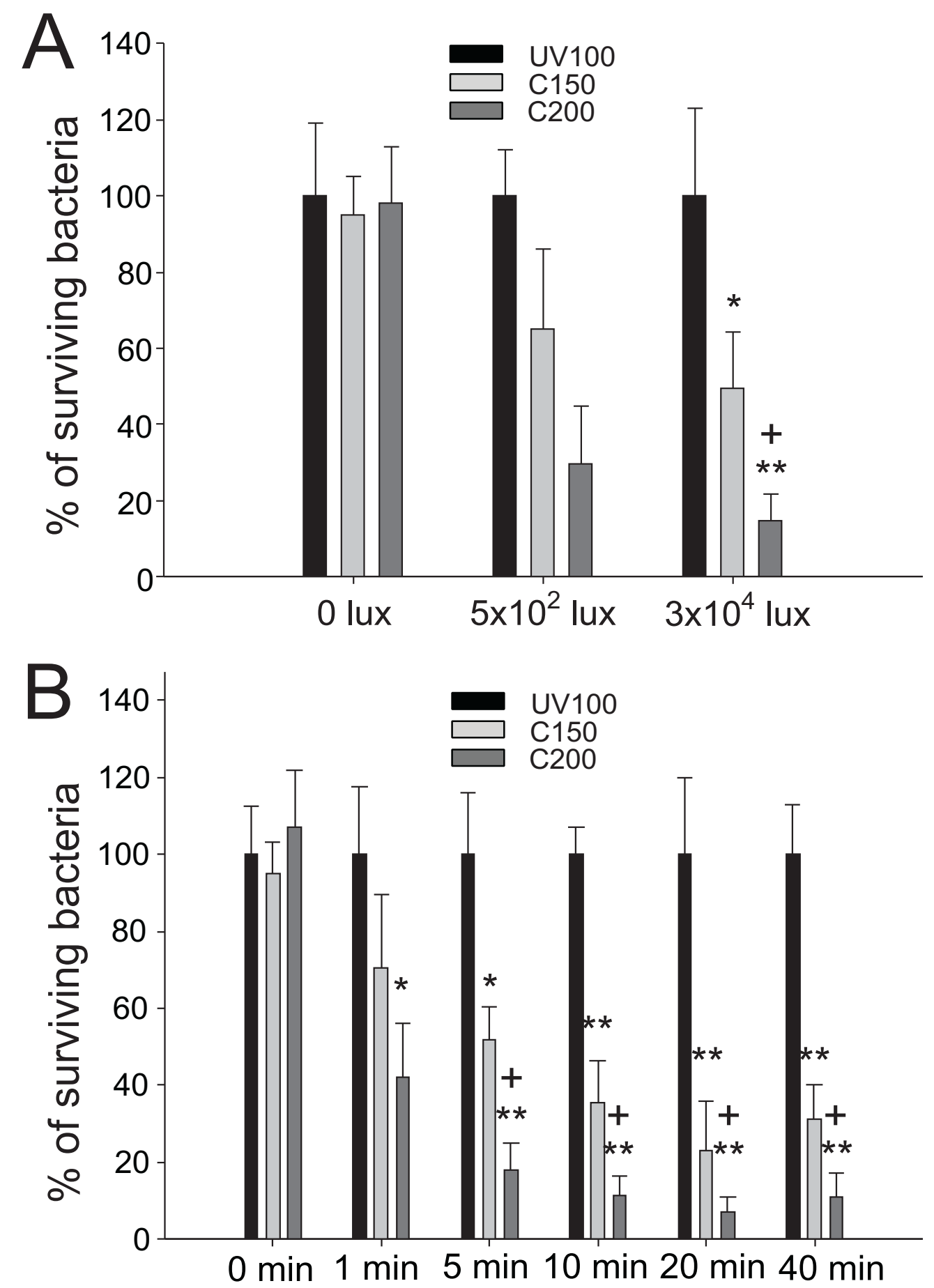

Figure 4

Dose dependency and kinetics. Dose dependency $(A)$ and kinetic $(B)$ analyses of the visible-light induced bactericidal activity against $\mathrm{S}$. aureus of $\mathrm{TiO}_{2}$-related photocatalyst substrates were shown. Illumination was carried out either at different light densities for $5 \mathrm{~min}(\mathrm{~A})$ or at a light density of $3 \times 10^{4}$ lux for different times $(B)$. In each illumination condition, the percentages of the surviving bacteria in $\mathrm{CI} 50$ and $\mathrm{C} 200$ groups were normalized to the percentage of the surviving bacteria in the UVI00 groups $(100 \%)$. $* P<0.05$ and $* * P<0.01$ compared to the respective UVIO0 groups. $+P<0.05$ compared to the respective $\mathrm{CI} 50$ groups. 


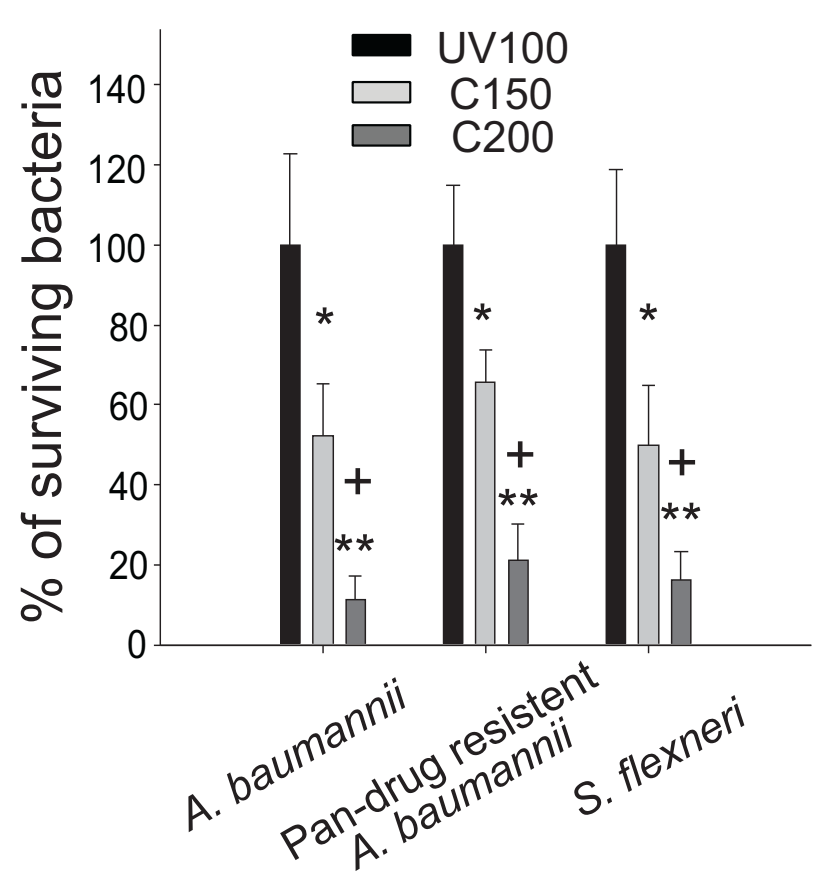

Figure 5

Pathogen analysis. For each pathogen, the percentage of surviving bacteria on the $\mathrm{C} 150$ and $\mathrm{C} 200$ substrates was normalized to that on the UVIO0 substrates. Illumination was performed at light density of $3 \times 10^{4}$ lux for $10 \mathrm{~min}$. $* P<$ 0.05 and $* * P<0.01$ compared to the respective UVI00 groups. $+P<0.05$ compared to the respective $\mathrm{CI} 50$ groups.

In conclusion, we found that by generating mixed-phase $\mathrm{TiO}_{2}$ nanocrystals, the antibacterial activity of carbon-containing photocatalyst was significantly enhanced; and the photocatalysts can be used in the visible light settings. Although the bactericidal activity remains to be further improved and optimized, the unique property of C200 to interact with bacteria might provide a new perspective for developing more effective antibacterial photocatalysts.

\section{Competing interests}

The authors declare that they have no competing interests.

\section{Authors' contributions}

CLC carried out the Raman spectra and confocal Raman mapping, and participated in its design. DSS and WCC carried out the photocatalysis experiments. YHT participated in the synthesis of photocatalysts. $\mathrm{HCH}$ participated in the SEM analysis. JBW and PHC participated in the confocal Raman mapping. JHC, PJT, NTL and MSU participated in the analysis of pathogenic bacteria. HHC conceived of the study, and participated in its design, coordination and drafted the manuscript. All authors read and approved the final manuscript.

\section{Acknowledgements}

The authors appreciate the financial support of National Science Council of Taiwan ROC under grant Nos. NSC 95-23।4-B-320 -009-MY3 and NSC 95-2120-M-259-003.

\section{References}

I. Russell AD: Bacterial adaptation and resistance to antiseptics, disinfectants and preservatives is not a new phenomenon. J Hosp Infect 2004, 57:97-104.

2. Russell AD: Biocide use and antibiotic resistance: the relevance of laboratory findings to clinical and environmental situations. Lancet Infect Dis 2003, 3:794-803.

3. Aiello AE, Larson E: Antibacterial cleaning and hygiene products as an emerging risk factor for antibiotic resistance in the community. Lancet Infect Dis 2003, 3:50 I-506.

4. Maness PC, Smolinski S, Blake DM, Huang Z, Wolfrum EJ, et al.: Bactericidal activity of photocatalytic $\mathrm{TiO}(2)$ reaction: toward an understanding of its killing mechanism. Appl Environ Microbiol 1999, 65:4094-4098.

5. Fujishima A, Honda K: Electrochemical photolysis of water at a semiconductor electrode. Nature 1972, 238:37-38.

6. Jacoby WA, Maness PC, Wolfrum EJ, Blake DM, Fennel JA: Mineralization of bacterial cell mass on a photocatalytic surface in air. Environ Sci Technol 1998, 32:2650-2653.

7. Legrini O, Oliveros E, Braun AM: Photochemical processes for water treatment. Chem Rev 1993, 93:67I-698.

8. Iwasaki M, Hara M, Kawada H, Tada H, Ito S: Cobalt Ion-Doped TiO(2) Photocatalyst Response to Visible Light. J Colloid Interface Sci 2000, 224:202-204.

9. Asahi R, Morikawa T, Ohwaki T, Aoki K, Taga Y: Visible-light photocatalysis in nitrogen-doped titanium oxides. Science 200I, 293:269-27I.

10. Ohno T, Sarukawa K, Matsumura M: Photocatalytic Activities of Pure Rutile Particles Isolated from TiO2 Powder by Dissolving the Anatase Component in HF Solution. J Phys Chem B 2001, 105:2417-2420.

II. Ohno T, Sarukawa K, Tokieda K, Matsumura M: Morphology of a TiO2 Photocatalyst (Degussa, P-25) Consisting of Anatase and Rutile Crystalline Phases. J Catalysis 200I, 203:82-86.

12. Chou PW, Treschev S, Chung PH, Cheng CL, Tseng YH, et al:: Observation of carbon-containing nanostructured mixed titania phases for visible-light photocatalysts. Applied physics letters 2006, 89:131919.

13. Wong MS, Chu WC, Sun DS, Huang HS, Chen JH, et al:: Visiblelight-induced bactericidal activity of nitrogen-doped titania photocatalyst in eliminating the human pathogens. Appl Environ Microbiol 2006, 72:6111-6116.

14. Li Q, Xie R, Li YW, Mintz EA, Shang JK: Enhanced visible-lightinduced photocatalytic disinfection of $E$. coli by carbon-sensitized nitrogen-doped titanium oxide. Environ Sci Technol 2007, 4I:5050-5056.

15. Yu JC, Ho W, Yu J, Yip H, Wong PK, et al.: Efficient visible-lightinduced photocatalytic disinfection on sulfur-doped nanocrystalline titania. Environ Sci Technol 2005, 39: I I75-I I 79.

16. McDonnell G, Russell AD: Antiseptics and disinfectants: activity, action, and resistance. Clin Microbiol Rev 1999, I 2:147- 179.

17. Egerton TA, Kosa SA, Christensen PA: Photoelectrocatalytic disinfection of E. coli suspensions by iron doped TiO2. Phys Chem Chem Phys 2006, 8:398-406.

18. Vohra A, Goswami DY, Deshpande DA, Block SS: Enhanced photocatalytic inactivation of bacterial spores on surfaces in air. J Ind Microbiol Biotechnol 2005, 32:364-370.

19. Salyers AA, Whitt DD: Bacterial pathogenesis: a molecular approach. Washington, D. C.: ASM Press; 1994:122-129.

20. Martino MC, Rossi G, Martini I, Tattoli I, Chiavolini D, et al.: Mucosal lymphoid infiltrate dominates colonic pathological changes in murine experimental shigellosis. J Infect Dis 2005, 192:|36-| 48.

21. Lima AA: Tropical diarrhoea: new developments in traveller's diarrhoea. Curr Opin Infect Dis 200 I, I 4:547-552.

22. Wong HC, Liu SH, Wang TK, Lee CL, Chiou CS, et al:: Characteristics of Vibrio parahaemolyticus O3:K6 from Asia. Appl Environ Microbiol 2000, 66:3981-3986. 
23. Chiou CS, Hsu WB, Wei HL, Chen JH: Molecular epidemiology of a Shigella flexneri outbreak in a mountainous township in Taiwan, Republic of China. J Clin Microbiol 2001, 39:1048-1056.

24. Navon-Venezia S, Ben-Ami R, Carmeli Y: Update on Pseudomonas aeruginosa and Acinetobacter baumannii infections in the healthcare setting. Curr Opin Infect Dis 2005, I 8:306-313.

25. Treschev SY, Chou PW, Tseng YH, Wang JB, Perevedentseva EV, et al.: Photoactivities of the visible-light-activated mixed-phase carbon-containing titanium dioxide: The effect of carbon incorporation. Applied Catalysis B: Environmental 2007, 79:8-16.

26. Tseng YH, Kuo CS, Huang CH, Li YY, Chou PW, et al:: Visible-lightresponsive nano-TiO2 with mixed crystal lattice and its photocatalytic activity. Nanotechnology 2006, I 7:2490-2497.

27. Chang $\mathrm{HH}$, Lin $\mathrm{CH}$, Lo SJ: Recombinant rhodostomin substrates induce transformation and active calcium oscillation in human platelets. Exp Cell Res 1999, 250:387-400.

28. Chang $\mathrm{HH}$, Lo SJ: Full-spreading platelets induced by the recombinant rhodostomin are via binding to integrins and correlated with FAK phosphorylation. Toxicon 1998 36: 1087-1099.

29. Sun DS, Lo SJ, Lin CH, Yu MS, Huang CY, et al.: Calcium oscillation and phosphatidylinositol 3-kinase positively regulate integrin alpha(IIb)beta3-mediated outside-in signaling. J Biomed Sci 2005, I 2:321-333.

30. Sun DS, Lo S], Tsai WJ, Lin CH, Yu MS, et al.: PI3-kinase is essential for ADP-stimulated integrin alpha(Ilb)beta3-mediated platelet calcium oscillation, implications for $\mathrm{P} 2 \mathrm{Y}$ receptor pathways in integrin alpha(IIb)beta3-initiated signaling cross-talks. J Biomed Sci 2005, I 2:937-948.

31. Kau JH, Sun DS, Tsai WJ, Shyu HF, Huang HH, et al.: Antiplatelet Activities of Anthrax Lethal Toxin Are Associated with Suppressed p42/44 and p38 Mitogen-Activated Protein Kinase Pathways in the Platelets. J Infect Dis 2005, I 92:|465-|474.

32. Murray PR, Baron EJ, Jorgensen JH, Pfaller MA, Yolken RH: Manual of clinical microbiology. Washington, D.C.: American Society for Microbiology; 2003.

33. Sliney $\mathrm{DH}$ : Optical radiation safety of medical light sources. Phys Med Biol 1997, 42:981-996.

34. Hearing V]: Biogenesis of pigment granules: a sensitive way to regulate melanocyte function. J Dermatol Sci 2005, 37:3-I4.

35. Slominski A, Pawelek J: Animals under the sun: effects of ultraviolet radiation on mammalian skin. Clin Dermatol 1998 1 6:503-5 I5.

36. Kisch H, Macyk W: Visible-light photocatalysis by modified titania. Chemphyschem 2002, 3:399-400.

37. Hashimoto K, Irie H, Fujishima A: TiO2 Photocatalysis: A Historical Overview and Future Prospects. Japanese Journal of Applied Physics 2005, 44:8269-8285.

38. Rana S, Rawat J, Sorensson MM, Misra RD: Antimicrobial function of Nd3+-doped anatase titania-coated nickel ferrite composite nanoparticles: a biomaterial system. Acta Biomater 2006, 2:421-432

39. Sunkara BK, Misra RD: Enhanced antibactericidal function of W4+-doped titania-coated nickel ferrite composite nanoparticles: a biomaterial system. Acta Biomater 2008, 4:273-283.

40. Rana S, Rawat J, Misra RD: Anti-microbial active composite nanoparticles with magnetic core and photocatalytic shell: TiO2-NiFe2O4 biomaterial system. Acta Biomater 2005, I:691-703.

41. Rana S, Srivastava RS, Sorensson MM, Misra RD: Synthesis and characterization of nanoparticles with magnetic core and photocatalytic shell: Anatase TiO2-NiFe204 system. Materials Science and Engineering B 2005, I I 9: |44- I 5 I.

42. Rawat J, Rana S, Sorensson MM, Misra RD: Anti-microbial activity of doped anatase titania coated nickel ferrite composite nanoparticles. Materials Science and Technology 2007, 23:97-102.

43. Rawat J, Rana S, Srivastava RS, Misra RD: Antimicrobial activity of composite nanoparticles consisting of titania photocatalytic shell and nickel ferrite magnetic core. Materials Science and Engineering C 2007, 27:540-545.

44. Mitoraj D, Janczyk A, Strus M, Kisch H, Stochel G, et al:: Visible light inactivation of bacteria and fungi by modified titanium dioxide. Photochem Photobiol Sci 2007, 6:642-648.

45. Rengifo-Herrera JA, Mielczarski E, Mielczarski J, Castillo NC, Kiwi J, et al.: Escherichia coli inactivation by $\mathbf{N}, \mathbf{S}$ co-doped commer- cial TiO2 powders under UV and visible light. Applied Catalysis B: Environmental 2008, 84:448-456.

46. Kau JH, Sun DS, Huang HH, Wong MS, Lin HC, et al.: Role of visible light-activated photocatalyst on the reduction of anthrax spore-induced mortality in mice. PLOS ONE 2009, 4:e4I67.

47. Yu JXZ: Effect of surface treatment on the photocatalytic activity and hydrophilic property of the sol-gel derived $\mathrm{TiO}_{2}$ thin films. Materials Research Bulletin 2001, 36:97-107.

48. Tryba B: Increase of the photocatalytic activity of $\mathrm{TiO}_{2}$ by carbon and iron modifications. International Journal of Photoenergy 2008: I-I5

49. Sousa SR, Moradas-Ferreira $\mathrm{P}$, Barbosa MA: TiO2 type influences fibronectin adsorption. J Mater Sci Mater Med 2005, I 6: I I73-I|78.

50. Inagaki $M$, Hirose $Y$, Matsunaga $T$, Tsumura $T$, Toyoda $M$ : Carbon coating of anatase-type $\mathrm{TiO} 2$ through their precipitation in PVA aqueous solution. Carbon 2003, 41:2619-2624.

Publish with Bio Med Central and every scientist can read your work free of charge

"BioMed Central will be the most significant development for disseminating the results of biomedical research in our lifetime. "

Sir Paul Nurse, Cancer Research UK

Your research papers will be:

- available free of charge to the entire biomedical community

- peer reviewed and published immediately upon acceptance

- cited in PubMed and archived on PubMed Central

- yours - you keep the copyright

Submit your manuscript here:

http://www.biomedcentral.com/info/publishing_adv.asp
BioMedcentral 